University of Nebraska - Lincoln

DigitalCommons@University of Nebraska - Lincoln

Faculty Publications, Department of Psychology

Psychology, Department of

2010

Development and Initial Psychometric Properties of the Computer Assisted Maltreatment Inventory (CAMI): A Comprehensive SelfReport Measure of Child Maltreatment History

\author{
David K. DiLillo \\ University of Nebraska-Lincoln, ddilillo@unl.edu \\ Sarah A. Hayes-Skelton \\ University of Massachusetts Boston \\ Michelle A. Fortier \\ University of California - Irvine \\ Andrea R. Perry \\ Palo Alto VA Healthcare System \\ Sarah E. Evans \\ University of Massachusetts Boston \\ See next page for additional authors \\ Follow this and additional works at: https://digitalcommons.unl.edu/psychfacpub \\ Part of the Psychiatry and Psychology Commons
}

DiLillo, David K.; Hayes-Skelton, Sarah A.; Fortier, Michelle A.; Perry, Andrea R.; Evans, Sarah E.; Messman Moore, Terri L.; Walsh, Kate; Nash, Cindy; and Fauchier, Angèle, "Development and Initial Psychometric Properties of the Computer Assisted Maltreatment Inventory (CAMI): A Comprehensive Self-Report Measure of Child Maltreatment History" (2010). Faculty Publications, Department of Psychology. 577. https://digitalcommons.unl.edu/psychfacpub/577

This Article is brought to you for free and open access by the Psychology, Department of at DigitalCommons@University of Nebraska - Lincoln. It has been accepted for inclusion in Faculty Publications, Department of Psychology by an authorized administrator of DigitalCommons@University of Nebraska - Lincoln. 


\section{Authors}

David K. DiLillo, Sarah A. Hayes-Skelton, Michelle A. Fortier, Andrea R. Perry, Sarah E. Evans, Terri L. Messman Moore, Kate Walsh, Cindy Nash, and Angèle Fauchier 


\title{
Development and initial psychometric properties of the Computer Assisted Maltreatment Inventory (CAMI): A comprehensive self-report measure of child maltreatment history
}

\author{
David DiLillo $^{\mathrm{a}, *}$, Sarah A. Hayes-Skelton ${ }^{\mathrm{a}, 1}$, Michelle A. Fortier ${ }^{\mathrm{a}, 2}$, Andrea R. Perry ${ }^{\mathrm{a}, 3}$, \\ Sarah E. Evans ${ }^{\mathrm{a}, 1}$, Terri L. Messman Moore ${ }^{\mathrm{b}}$, Kate Walsh ${ }^{\mathrm{a}}$, Cindy Nash $^{\mathrm{a}, 4}$, Angèle Fauchier $^{\mathrm{c}}$ \\ a University of Nebraska-Lincoln, Lincoln, NE, USA \\ b Miami University, Oxford, OH, USA \\ c Family Research Laboratory, University of New Hampshire, Durham, NH, USA
}

\section{A R T I C L E I N F O}

\section{Article history:}

Received 31 July 2008

Received in revised form 20 July 2009

Accepted 8 September 2009

Available online 26 March 2010

\section{Keywords:}

Child maltreatment

Child abuse

Sexual abuse

Physical abuse

Psychological abuse

Neglect

Assessment

Retrospective

\begin{abstract}
A B S T R A C T
Objectives: The present study reports on the development and initial psychometric properties of the Computer Assisted Maltreatment Inventory (CAMI), a web-based self-report measure of child maltreatment history, including sexual and physical abuse, exposure to interparental violence, psychological abuse, and neglect.

Methods: The CAMI was administered to a geographically diverse sample of college students $(N=1398)$. For validation purposes, participants also completed a widely used measure of maltreatment (Childhood Trauma Questionnaire) as well as measures of social desirability. To examine test-retest reliability, a subset of participants $(n=283)$ completed the CAMI a second time 2-4 weeks after the initial administration.

Results: Short-term test-retest reliability of the CAMI subscales was good to strong, as was internal consistency on applicable scales. Criterion-related validity of the CAMI's composite abuse severity scores was supported through predicted discriminative correlations with subscales of the CTQ. The CAMI subscales showed comparable or weaker associations with measures of social desirability than did the CTQ. Although both measures were more strongly associated with a need for approval than other aspects of social desirability, these correlations were still rather low in magnitude and in a range typical of many clinical measures.

Conclusions: The present findings as well as the rich descriptive data and flexibility offered by computer administration suggest that the CAMI is a promising instrument for the comprehensive assessment of maltreatment history from adults.
\end{abstract}

(c) 2010 Elsevier Ltd. All rights reserved.

\footnotetext{
is This project was funded in part by a Layman Award from the University of Nebraska-Lincoln to the first author.

* Corresponding author address: University of Nebraska-Lincoln, Department of Psychology, 238 Burnett Hall, Lincoln, NE 68588, USA.

1 Present address: Department of Psychology, University of Massachusetts-Boston, Boston, MA, USA.

2 Present address: Department of Anesthesiology \& Perioperative Care, University of California-Irvine and Department of Pediatric Psychology, Children's Hospital of Orange County, CA, USA.

3 Present address: Palo Alto VA Healthcare System, Palo Alto, CA, USA.

4 Present address: Lincoln Regional Center, Lincoln, NE, USA.
} 


\section{Introduction}

Much of our current understanding about child maltreatment and its long-term correlates comes from studies using retrospective assessments in which adults report about their own child maltreatment experiences. For example, the wellestablished associations between early abuse and adult psychopathology have been revealed primarily through retrospective self-report surveys (e.g., Molnar, Buka, \& Kessler, 2001; Nelson et al., 2002). Unfortunately, considering the prevalence and importance of studies using retrospective methods, too little attention has been paid to development of psychometrically sound measures that provide comprehensive information about a range of child abuse experiences. Although there are exceptions (e.g., Higgins \& McCabe, 2001; Smith, Lam, Bifulco, \& Checkley, 2002), researchers often have relied on "homemade" measures of a single abuse type-instruments with few or no known psychometric properties. In reviewing measures for assessing childhood sexual abuse (CSA), Hulme (2004) noted that 50\% of 116 total studies used instruments constructed by their authors; only one of these studies offered any psychometric support beyond face validity. Similarly, a review of retrospective questionnaires revealed that only one child maltreatment measure had been validated using an independent criterion (Roy \& Perry, 2004). To help address this problem, we have initiated the development of the Computer Assisted Maltreatment Inventory (CAMI), a web-based instrument designed to assess all major forms of child maltreatment, including physical abuse, sexual abuse, psychological abuse, neglect, and exposure to interparental violence (IPV). Development of the CAMI is an ongoing process. Prior studies have compared mode of administration of the CAMI (DiLillo, DeGue, Kras, Di Loreto-Colgan, \& Nash, 2006) and issues of sensitivity and specificity in detecting abuse (DiLillo et al., 2006b). The current paper details the next step in the CAMI's development by providing initial reliability and validity data from a large, geographically diverse sample of college students, who are among the most commonly studied populations in retrospective studies of child maltreatment (Rind, Tromovitch, \& Bauserman, 1998).

\section{Description of the Computer Assisted Maltreatment Inventory (CAMI)}

Assessment of multiple maltreatment types. A common practice in past research is to assess only the form of maltreatment that is of primary interest in a given study. However, recent findings suggest that the assessment of single abuse types in overly narrow. Rather than occurring in isolation, abuse types frequently overlap and tend to have a cumulative impact on later functioning (e.g., Clemmons, DiLillo, Martinez, DeGue, \& Jeffcott, 2003; Dong et al., 2004; Higgins \& McCabe, 2001). Further, exposure to IPV (also called "witnessing domestic violence") often co-occurs with other abuse types (Appel \& Holden, 1998) and is considered part of the constellation of abusive experiences that predict long-term psychosocial problems (Kitzmann, Gaylord, Holt, \& Kenny, 2003). This emerging picture of overlapping abuse types and their additive impact underscores a need for researchers to account for all forms of abuse.

A behaviorally specific, multidimensional view of maltreatment. The CAMI uses behaviorally specific items to assess each abuse type. This approach has been advocated on both theoretical and empirical grounds as superior to those using more subjective, participant-defined criteria, which tend to produce lower reporting rates (e.g., Fricker, Smith, Davis, \& Hanson, 2003; Silvern, Waelde, Baughan, Karyl, \& Kaersvang, 2000). In addition to simply detecting whether maltreatment has occurred, the CAMI's behaviorally specific items assess key aspects of abuse experiences, including the nature and frequency of abusive acts, perpetrator identity, age at onset and termination of abuse, methods of coercion, and any resulting injuries. This approach is supported by results linking each of these dimensions to increased short-term (e.g., English et al., 2005) and more enduring negative outcomes (e.g., Bifulco, Moran, Baines, Bunn, \& Stanford, 2002). Together, the empirically relevant dimensions assessed by the CAMI produce a continuous measure of severity that not only expands the range of research questions that can be addressed (e.g., possible "dose-response" effects of abuse; Anda et al., 2006), but also increases statistical power (compared to dichotomization).

To accommodate differences in the way researchers define maltreatment types, the CAMI's structure also allows flexibility in operationalizing each form of abuse. In the case of sexual abuse, for example, studies vary in the upper age used to define "childhood," in whether non-contact activities like exhibitionism are classified as abuse, and in whether minimum perpetrator-victim age difference should be part of the definition. Similar questions characterize the definition of exposure to IPV (Mohr, Noone Lutz, Fantuzzo, \& Perry, 2000), including whether "exposure" should be limited to actually witnessing interparental violence, or whether hearing such acts or simply seeing the aftermath (e.g., a mother's bruised face) should constitute exposure. Underlying issues of definitional variability is the notion that concepts of child maltreatment and adequacy of parenting are socially constructed and influenced by norms that vary across time, communities, and cultural contexts (D’Cruz, 2004; Lowe, Pavkov, Casanova, \& Wetchler, 2005). Thus, it is important that instruments can be adapted to operationalize maltreatment in accordance with the aims and theoretical basis of a particular study.

\section{Focus of the present study}

Despite its potential strengths, the CAMI's utility depends on a demonstration of acceptable psychometric properties, including strong test-retest and internal reliability, criterion-related validity, and freedom from social desirability biases. Although concordance rates ranging from $81 \%$ to $91 \%$ have been found for the temporal stability of self-reported sexual abuse for intervals spanning 2 weeks to 2 years (e.g., Friedrich, Talley, Panser, Fett, \& Zinsmeister, 1997), it is unknown whether 
similar stability exists in the reporting of other abuse types or specific abuse dimensions (nature, frequency, duration, perpetrator identity). One goal of this study is to examine whether detailed aspects of abuse history are reported similarly across time.

To evaluate criterion validity, the CAMI was compared to the Childhood Trauma Questionnaire (CTQ; Bernstein \& Fink, 1998), a widely used abuse history measure with strong validation data and continuous severity scores assessing abuse types similar to those on the CAMI. In a preliminary study examining only the detection of sexual and physical abuse, relatively high agreement emerged between the CAMI and CTQ victim classifications (92\% and 80\% agreement for sexual and physical abuse, respectively; DiLillo et al., 2006b). Here, we report associations for the severity of each abuse type across the two instruments. We expected that the measures' severity scores would be positively related, but that the strongest associations would be found between similar maltreatment subscales.

One threat to the validity of self-report instruments is socially desirable response bias, which has been linked to decreased reporting of various types of sensitive information (Meston, Heiman, Trapnell, \& Paulhus, 1998) and spousal abuse (Dutton \& Hemphill, 1992). Regarding child maltreatment, the CTQ has been found to have weak associations with social desirability among college students (Bernstein \& Fink, 1998). Here, CAMI and CTQ responses are examined in relation to multiple measures of social desirability. Because the CAMI's behaviorally descriptive items query about highly sensitive information, we expected stronger associations between social desirability and abuse reporting on the CAMI as opposed to the CTQ.

\section{Method}

\section{Participants}

Participants included 1398 undergraduate students ( $n=1015$ women and 383 men) recruited from psychology courses at three geographically diverse universities, including the University of Nebraska-Lincoln (UNL; $n=481$ ), Miami University (MU; $n=416$ ), and the University of Southern California (USC; $n=501$ ). Participants were, on average, 20.3 years old $(S D=2.3$ ). The majority were European American (76.2\%), while 9.0\% were Asian American, 5.2\% Hispanic/Latino, 3.4\% African American, 0.2\% Native American, 0.2\% Hawaiian/Pacific Islander, and 5.9\% reporting multiple ethnicities. Most participants reported middle or upper class family incomes while growing up, with $73 \%$ reporting a family income of greater than US\$50,000. Finally, a demographically similar subset of the overall sample ( $n=281 ; 215$ women, 66 men) was recruited during the initial data collection to complete the CAMI a second time for the purpose of evaluating test-retest reliability. These participants were mainly from UNL $(n=113)$ and USC $(n=163)$, with fewer coming from MU $(n=5)$ due to a later start date.

\section{Measures}

\section{Computer Assisted Maltreatment Inventory.}

Overall structure of the Computer Assisted Maltreatment Inventory (CAMI). The CAMI is a web-based instrument designed to assess maltreatment history from adults age 18 and over. Five subtypes of maltreatment are included on the CAMI: sexual, physical, and psychological abuse; neglect; and exposure to IPV. For sexual abuse, physical abuse, and exposure to IPV, participants respond to a series of behaviorally specific screener questions that reveal whether they experienced a range of abusive acts prior to age 18 . Subsequent questions assess specific dimensions of the abuse (referred to as "severity indicators"), including the nature, frequency, and duration of activities, as well as the degree of force used, types of manipulation that were involved, and resulting injuries. These queries are repeated in sequence for each identified perpetrator, after which respondents are automatically directed to the next maltreatment subscale. Branching and skip patterns are programmed into the CAMI so that only questions relevant to each participant's abuse experience are administered. Because psychological abuse and neglect manifest in a broader range of parental behaviors encompassing acts of both commission and omission, these forms of maltreatment are not amenable to a format using screener and follow-up questions. Rather, to capture these experiences, participants rate various negative and positive (reverse scored) parenting behaviors on a five-point Likert-type scale reflecting level of experience with each behavior. Completion time for the CAMI is 10-30 min, depending on the type and extent of abuse reported. Detailed descriptions of each subscale are presented below.

Sexual abuse. To screen for child sexual abuse, participants are presented with a list of hands-on sexual acts varying in severity (e.g., kissing, fondling, intercourse) and are asked to indicate whether, before the age of 18 , they experienced any of these acts: (1) against their will; (2) with a family member, or; (3) with someone 5 or more years older. Participants are asked to exclude experiences that occurred during explorative play with a peer (e.g., playing doctor) or voluntary acts with a dating partner. Those who endorse one or more of the screeners are classified as potential victims and directed to in-depth followup questions asking participants to identify up to five perpetrators with whom the identified sexual acts occurred. For each perpetrator, participants indicate on a 5-point scale ( $1=$ never happened, $2=1-2$ times, $3=3-5$ times, $4=6-10$ times, $5=$ over 10 times) how frequently various behaviors (e.g., kissing, fondling, oral-genital contact, penetration) occurred. Participants also indicate age at onset and termination of abuse, reason the abuse ended, and types of verbal and physical coercion used.

For the purposes of this study, participants were considered victims of CSA if they endorsed one or more screener questions and if their follow-up responses conformed to the following operational definition of CSA. Using an age difference 
criterion employed by many previous researchers (see Rind et al., 1998 for a summary of definitional criteria), any sexual act, regardless of consent, involving inappropriate touching, kissing, or fondling of a participant under 14 with an individual more than 5 years older constitutes CSA. For participants ages 14-17, acts occurring with a perpetrator 10 or more years older are considered CSA, regardless of consent. In addition, explicitly sexual acts involving a family member (excluding sex play or exploration) are classified as CSA. Finally, any sexual experience that was nonconsensual (either coerced or forced) and involved physical contact (i.e., kissing, sexual touching, or oral, anal, or vaginal intercourse) was classified as CSA.

Physical abuse. Screeners on this subscale inquire about the occurrence of physically aggressive acts by a parent or caregiver before age 18. Participants who endorse any of these acts (e.g., grabbed or shook you hard, threw or knocked you down, hit you with an open hand or fist) are asked to identify up to five individuals with whom the acts occurred. For each perpetrator, participants indicate the frequency of specific acts using a 5-point scale (ranging from $1=$ never happened to $5=$ more than 10 times). Participants also report resulting injuries, ranging in severity from cuts and bruises to broken bones and internal injuries, as well as any medical treatment they received. Participants indicate their age at the onset and termination of abuse, reasons the acts ended, and why they believe each perpetrator committed the acts.

In the present study, child physical abuse (CPA) was determined by sliding cut scores along two dimensions: the severity and frequency of the acts. Less severe acts occurring with greater frequency and more severe acts occurring with lesser frequency can each "cross the line" beyond normative parental behaviors into the realm of abuse (Whipple \& Richey, 1997). Here, classifications of CPA were made if a participant reported any of the following: low severity acts (e.g., grabbing, pinching, pushing, shaking, spanking) occurring 10 or more times, moderate severity acts (e.g., hit with an object) on three or more occasions, or a high severity act (e.g., being choked, threatened with a weapon) one or more times.

Exposure to interparental violence (IPV). This scale starts with 17 pairs of screener statements describing physically aggressive acts that can occur between parents or parental figures. These items are similar in structure to the Conflict Tactics Scales- 2 (Straus, Hamby, Boney-McCoy, \& Sugarman, 1996; e.g., father punched mother or mother punched father). An additional item assessing verbal/emotional abuse occurring between parents is also included. To assess level of exposure to violence, participants select one of four options for each item: $1=I$ was in the room or area and saw this happen; $2=I$ was close by and heard this happen but did not see it; $3=I$ was gone when this happened but heard about it later; $4=$ This activity never occurred between my parents. Those who respond with a 1, 2, or 3 to any item are considered to have been exposed to violence and are directed to questions assessing the age at which the exposure to violence began and ended, the frequency of witnessing IPV, recollection of whether alcohol was a factor, whether injuries resulted from the acts, and, if so, whether medical attention was sought.

Psychological abuse. Psychological abuse items were generated by a team of researchers that included one doctoral-level child maltreatment expert and two student research assistants who completed extensive readings of the theoretical literature on psychological abuse. Items were generated independently by each team member using Hart, Brassard, Binggeli, and Davidson's (2002) well-known model of psychological abuse as a guide. Items were compared for similarities in content across the three authors' examples. A preliminary pool of 57 items was created through group consensus and reduced to 24 items though factor analysis (see Nash, 2006, available electronically from the corresponding author). Factor loadings for items corresponded closely to the psychological maltreatment subtypes proposed in the Hart et al. model and include: denying emotional responsiveness, terrorizing/spurning, and corrupting. An additional factor reflecting overly demanding or rigid parental behaviors also emerged. For the present study, however, only the total psychological abuse score was used. Each item is rated on a five-point scale ( $1=$ strongly disagree to $5=$ strongly agree). Sample items include: "My parents only paid attention to me when they needed something from me" (denying emotional responsiveness); "My parents threatened to hit or physically hurt me" (terrorizing/spurning); “I used illegal drugs with my parents" (corrupting); “My parents were very controlling" (overly demanding/rigid).

Neglect. Neglect items were developed in the same manner as the psychological abuse items. The final 20 items comprise 5 subscales derived through factor analysis from a larger pool of 38 items (Nash et al., 2006). These scales correspond to subtypes of neglect commonly identified in the literature (e.g., Sedlak \& Broadhurst, 1996), and include: basic needs, cleanliness, abandonment, supervision/monitoring, and medical neglect. Sample items are: "I missed meals as a child" (basic needs); "Bedding and towels were washed regularly when I was a child"(cleanliness; reverse scored); "Sometimes my parents forgot about me when I stayed overnight with a friend or relative" (abandonment); "My parents did not make me go to school if I did not want to"(monitoring); and "My parents took me to the doctor when I needed to go"; (medical, reverse scored). Each item is rated on a 5-point scale ( $1=$ strongly disagree to $5=$ strongly agree). Only the neglect total score was used in the present study.

Scoring of abuse severity. In addition to binary (presence versus absence) abuse classifications, the CAMI produces continuous scores reflecting the severity of each abuse type, as well as a total maltreatment severity score representing the cumulative severity across all individual forms of abuse. For sexual abuse, physical abuse, and exposure to IPV, severity scores reflect the sum of 6 severity indicators. For example, the severity indicators making up the sexual abuse score are: relationship to the perpetrator, frequency of abusive acts, nature of the acts, duration of activities, use of physical force, and number of 
Table 1

Scoring of abuse severity indicators.

\begin{tabular}{|c|c|c|c|}
\hline & Child sexual abuse & Child physical abuse & Exposure to IPV \\
\hline \multirow[t]{3}{*}{ Perpetrator } & 1 = Non-family & 1 = Non-family & $\begin{array}{l}1 \text { = Father or mother physical } \\
\text { only }\end{array}$ \\
\hline & 2 = Family non-parent & 2 = Family non-parent & $\begin{array}{l}2=\text { Father and mother physical } \\
\text { only }\end{array}$ \\
\hline & $3=$ Parent & $3=$ Parent & $\begin{array}{l}3=\text { Mother or father (or both) } \\
\text { physical, plus verbal/emotional } \\
\text { abuse between parents }\end{array}$ \\
\hline \multirow{3}{*}{ Frequency } & $1=1-2$ times & $1=1-2$ times & 1 = Happened once \\
\hline & $2=3-10$ times & $2=3-10$ times & $2=$ Happened $2-10$ times \\
\hline & $3=>10$ times & $3=>10$ times & $3=$ Happened $>10$ times \\
\hline Level of exposure & - & - & $\begin{array}{l}1=\text { Was not present but heard } \\
\text { about abuse later/saw } \\
\text { aftereffects } \\
2=\text { Was close by and heard it, } \\
\text { but did not see it } \\
3=\text { Was in the room and saw it }\end{array}$ \\
\hline \multirow[t]{3}{*}{ Nature of acts } & $1=$ Non-contact & $\begin{array}{l}1 \text { = Grabbed, shook, slapped, } \\
\text { pinched, spanked on bottom } \\
\text { with/without object }\end{array}$ & $\begin{array}{l}\text { 1 = Grabbed, pushed, shook, } \\
\text { pulled }\end{array}$ \\
\hline & $2=$ Contact $/$ no penetration & $\begin{array}{l}2=\text { Punched, kicked, knocked } \\
\text { down, hard object thrown }\end{array}$ & $\begin{array}{l}2 \text { = Slapped, bit, hit with minor } \\
\text { object, threw something, } \\
\text { punched, kicked }\end{array}$ \\
\hline & $3=$ Penetration & $\begin{array}{l}3 \text { = Hit with hard object, } \\
\text { choked, beaten, burned, } \\
\text { threatened with weapon }\end{array}$ & $\begin{array}{l}3 \text { = Choked, hit with major } \\
\text { object, burned, threatened } \\
\text { with weapon, used weapon, } \\
\text { sexual assault }\end{array}$ \\
\hline \multirow[t]{3}{*}{ Duration } & 1 = Less than 1 year & 1 = Less than 1 year & 1 = Less than 1 year \\
\hline & $2=1-2$ years & $2=1-2$ years & $2=1-2$ years \\
\hline & $3=>2$ years & $3=>2$ years & $3=>2$ years \\
\hline Force/manipulation & $\begin{array}{l}0=\text { None } \\
1=\text { Verbal tactics } \\
2=\text { Threats of physical harm } \\
3=\text { Physically held down }\end{array}$ & - & - \\
\hline Injury/medical attention & - & $\begin{array}{l}1=\text { Bruises, bloody nose or lip, } \\
\text { cuts or scratches } \\
2=\text { Broken or fractured bones, } \\
\text { burns } \\
3=\text { Internal injuries, paralysis }\end{array}$ & $\begin{array}{l}0=\text { No medical attention and } \\
\text { no injuries } \\
1=\text { No medical attention, but } \\
\text { cuts and bruises } \\
2=\text { No medical attention but } \\
\text { black eye or bloody nose } \\
3=\text { Received medical attention } \\
\text { or had broken bones, internal } \\
\text { injuries, or burns }\end{array}$ \\
\hline Number of perpetrators & $\begin{array}{l}1=\text { One } \\
2=\text { Two } \\
3=\text { Three }\end{array}$ & $\begin{array}{l}1=\text { One } \\
2=\text { Two } \\
3=\text { Three }\end{array}$ & - \\
\hline Scoring range & $5-18$ & $6-18$ & $5-18$ \\
\hline
\end{tabular}

perpetrators. Each indicator is weighted from 1 to 3 with higher scores reflecting greater severity. Scores for each indicator are then summed to produce a severity score for each abuse type (maximum score $=18$ ). For participants reporting multiple perpetrators within an abuse type, the highest score on each severity indicator across perpetrators is used in calculating the total severity for that abuse type. See Table 1 for detailed scoring of severity indicators for sexual abuse, physical abuse, and exposure to IPV. For psychological abuse and neglect, severity scores are obtained by summing the Likert-type responses, resulting in raw score ranges of $0-96$ and $0-80$ on the psychological abuse and neglect scales, respectively. To give equal maximum weight to all abuse types, the raw scores on these scales are algebraically converted to the same 18-point metric used by the sexual and physical abuse and exposure to IPV scales. Finally, a total score reflecting the cumulative severity of all 5 abuse types is computed by summing the 5 abuse scale severity scores.

Childhood Trauma Questionnaire. The Childhood Trauma Questionnaire (CTQ) was originally developed as a 70-item instrument (Bernstein et al., 1994), which was reduced through factor analysis to 28 Likert-type items (Bernstein et al., 2003). The short version is designed to measure 5 subtypes of child maltreatment (i.e., physical, sexual, and emotional abuse; physical and emotional neglect) in a relatively brief amount of time (i.e., 5-7 min). Each abuse subscale is comprised of five items 
rated on a five-point scale, ranging from 1 (never true) to 5 (very often true) in response to the stem "When I was growing up ...". The CTQ generates dichotomous victim classification scores as well as a continuous score that provides an abuse severity indicator.

Reliability and validity of the CTQ subscales have been well-documented. Internal reliability coefficients for subscales range from .72 to .96 across adolescent psychiatric inpatient, adult psychiatric outpatient, and university student samples (Bernstein \& Fink, 1998). The CTQ has strong test-retest reliability across the subscales: physical abuse $=.80$, sexual abuse $=.81$, emotional abuse $=.80$, physical neglect $=.79$, and emotional neglect $=.81$ (mean interval 3.6 months). Construct validity of the brief version was established through a 2-step process initially involving exploratory factor analysis of the original CTQ items, followed by confirmatory factor analyses with the 2 original samples as well as two additional samples (Bernstein et al., 2003). Results supported measurement invariance by closely replicating the 5 factor structure of the abuse subscales across all 4 samples, which suggests that the measure holds the same meaning across diverse groups (Bernstein et al., 2003). Criterion-related validity was established in a psychiatric inpatient sample by comparing responses on the CTQ to independent data obtained from the participants' therapists. Therapists' ratings were based on sources including clinical interviews with patients and their families as well as information from referring clinicians and agencies. The CTQ latent maltreatment variables corresponded positively with analogous therapist ratings across all abuse types, lending support for the convergent and discriminant validity of the CTQ. Finally, the means of the latent abuse constructs on the CTQ short form tended to be higher for clinical participants relative to community participants.

Balanced inventory of desirable responding. The Balanced Inventory of Desirable Responding (BIDR; Paulhus, 1994) is a 40-item measure of socially desirable responding. Participants rate how much they agree with each statement on a 7-point scale (anchored from $1=$ not true to $7=$ very true) to yield a total social desirability score. The measure also produces summary scores for self-deceptive enhancement (SDE), which refers to the tendency to give "honest but positively biased" self-reports, and impression management (IM), which refers to the intentional faking of responses to create a socially desirable image (Paulhus, 1991, p. 37). Using Paulhus's (1994) recommendations, responses were scored by assigning 1 point only to extreme responses ( 6 or 7 ) on the 7-point Likert-type scale and summing points across items to form subscale scores. Higher total and subscale scores are indicative of greater social desirability. Psychometric properties for the BIDR are sound (Paulhus, 1991,1994 ), with high test-retest reliability (self-deception $=.69$; impression management $=.65$ ) and internal consistency (self-deception, range $=.68-.80$; impression management, range $=.68-.86$; overall social desirability, range $=.76-.83$ ). Factor analysis with college students provides support for the SDE and IM components (Paulhus, 1984).

Marlowe-Crowne Social Desirability Scale. The Marlowe-Crowne Social Desirability Scale (MCSDS; Crowne \& Marlowe, 1960) is a 33-item self-report questionnaire designed to measure social desirability. Participants are asked to respond true or false to a series of positive (e.g., "I'm always willing to admit when I made a mistake") and negative (e.g., "I sometimes think when people have a misfortune they only got what they deserved") statements. A total score is generated, with higher scores indicating greater socially desirable responding. Internal consistency for the MCSDS appears to be adequate, ranging from .53 to .79 depending on the sample utilized (Barger, 2002; Beretvas, Meyers, \& Leite, 2002). However, test-retest reliability results are mixed (with estimates falling between .38 and .88; Beretvas et al., 2002; see review by Paulhus, 1991). Comparisons of the MCSDS and the BIDR suggest that these instruments reflect slightly different constructs, with the MCSDS measuring participants' need to gain approval and the BIDR assessing both impression management and self-deceptive enhancement (Paulhus, 1991).

Procedure. Data collection involved a multi-site collaboration among UNL, MU, and USC. Each school's Institutional Review Board approved the study. Participants were recruited primarily from undergraduate psychology courses and received extra credit for participation. All measures were completed via computer, with the CAMI subscales presented first, in random order, followed by the other measures presented randomly. Participants received debriefing information with contact information of agencies providing sliding fee mental health services.

\section{Results}

Prevalence of abuse

Child sexual abuse. Using the behavioral criteria employed by the CAMI, 107 (8.0\%) of the 1333 individuals who provided information about sexual abuse history were classified as child sexual abuse victims. Average severity of abuse across the 107 victims was 10.31 ( $S D=2.64$; range $=6-18)$. Descriptive statistics for characteristics of sexual abuse experiences are provided in the first column of Table 2

. As would be expected, the modal response included having one extrafamilial perpetrator who used verbal tactics to commit a physical act not involving penetration, which occurred one time in a period of less than 1 year. However, a significant number of sexual abuse victims reported acts that involved penetration (42.1\%), being physically held down (38.5\%), or a duration of abuse lasting more than 2 years (20.6\%). 
Table 2

Prevalence and test-retest reliability across abuse characteristics on the CAMI.

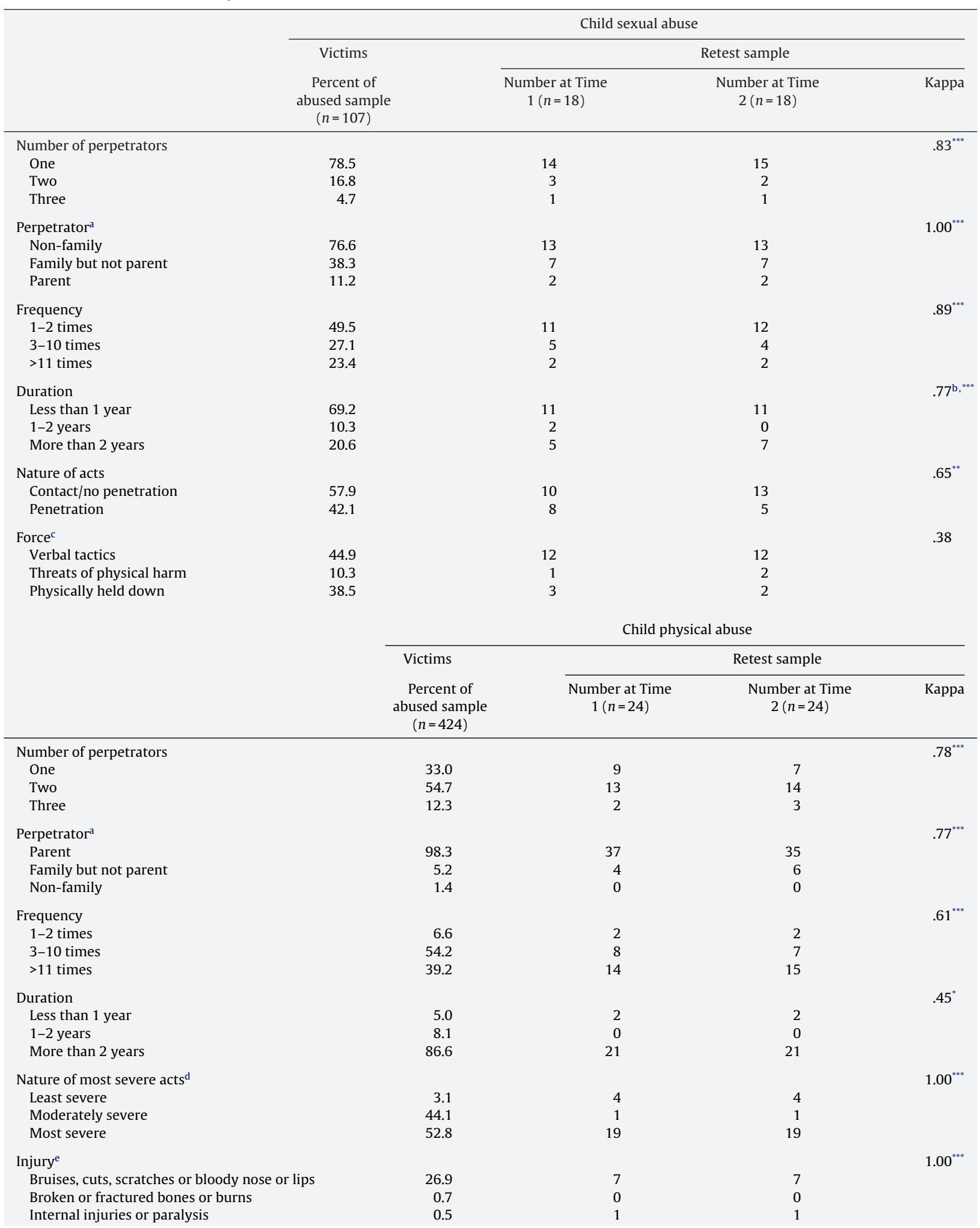




\begin{tabular}{|c|c|c|c|c|}
\hline & \multicolumn{4}{|c|}{ Exposure to IPV } \\
\hline & \multirow{2}{*}{$\begin{array}{l}\text { Victims } \\
\text { Percent of } \\
\text { abused sample } \\
\quad(n=231)\end{array}$} & \multicolumn{3}{|c|}{ Retest sample } \\
\hline & & $\begin{array}{l}\text { Number at Time } \\
\qquad 1(n=49)\end{array}$ & $\begin{array}{l}\text { Number at Time } \\
\qquad 2(n=49)\end{array}$ & Kappa \\
\hline \multicolumn{4}{|l|}{ Perpetrator } & $.78^{* * *}$ \\
\hline Father or mother & 38.2 & 19 & 18 & \\
\hline Both father and mother & 61.8 & 28 & 29 & \\
\hline \multicolumn{4}{|l|}{ Level of exposure } & $.42^{* *}$ \\
\hline Was close by and heard it, but did not see it & 19.9 & 10 & 12 & \\
\hline Was in the room and saw it & 80.1 & 39 & 37 & \\
\hline \multicolumn{4}{|l|}{ Frequency } & $.60^{* * *}$ \\
\hline 1 time & 23.6 & 11 & 13 & \\
\hline $2-10$ times & 39.6 & 23 & 23 & \\
\hline$>11$ times & 39.9 & 13 & 11 & \\
\hline \multicolumn{4}{|l|}{ Duration } & $.67^{* * *}$ \\
\hline Less than 1 year & 24.9 & 14 & 14 & \\
\hline $1-2$ years & 10.7 & 3 & 4 & \\
\hline More than 2 years & 64.4 & 30 & 29 & \\
\hline \multicolumn{4}{|l|}{ Nature of acts ${ }^{\mathrm{f}}$} & $.71^{* * *}$ \\
\hline Least severe & 35.1 & 16 & 16 & \\
\hline Moderately severe & 46.8 & 21 & 23 & \\
\hline Most severe & 18.2 & 12 & 10 & \\
\hline \multicolumn{4}{|l|}{ Medical attention ${ }^{g}$} & $.46^{* *}$ \\
\hline No medical attention but had cuts or bruises & 18.2 & 9 & 13 & \\
\hline $\begin{array}{l}\text { No medical attention but had black eye or } \\
\text { bloody nose }\end{array}$ & 8.2 & 4 & 2 & \\
\hline $\begin{array}{l}\text { Received medical attention or had broken } \\
\text { bones, internal injuries, or burns }\end{array}$ & 10.4 & 4 & 2 & \\
\hline \multicolumn{5}{|c|}{ a Percentages add up to more than $100 \%$ due to multiple perpetrators per victim. } \\
\hline \multirow{7}{*}{\multicolumn{5}{|c|}{$\begin{array}{l}\text { b To calculate this kappa, categories were combined into duration lasting less than a year and duration lasting more than a year. } \\
\text { c Seven individuals in the full sample and } 2 \text { in the retest sample did not respond to the force questions and therefore are not counted here. } \\
\text { d Least severe = grabbed, shook, slapped, pinched, spanked on bottom with or without an object; moderately severe= punched, kicked, knocked down, } \\
\text { or had a hard object thrown at; severe = hit with a hard object, choked, beaten, burned, threatened with a weapon. } \\
\text { e Three hundred and five individuals in the full sample and } 16 \text { in the retest sample reported experiencing no injuries and thus are not included here. } \\
\text { f Least severe = grabbed, pushed, shook, or pulled hair; moderately severe = slapped, bit, hit with a minor object, threw something, punched, or kicked; } \\
\text { most severe = choked, hit with a major object, burned, threatened with a weapon, used a weapon, or sexual assault. }\end{array}$}} \\
\hline & & & & \\
\hline & & & & \\
\hline & & & & \\
\hline & & & & \\
\hline & & & & \\
\hline & & & & \\
\hline \multirow{2}{*}{\multicolumn{5}{|c|}{$\begin{array}{l}g \text { One hundred and forty-six individuals in the full sample and } 32 \text { in the retest sample reporting that no injuries occurred or medical attention was } \\
\text { needed. }\end{array}$}} \\
\hline & & & & \\
\hline \multicolumn{4}{|c|}{${ }_{* *}^{*} p<.05$} & \\
\hline \multicolumn{5}{|l|}{$p<.001$} \\
\hline
\end{tabular}

Child physical abuse. Of the 1355 individuals who provided complete information about physical abuse history, 424 (31.3\%) were classified as victims of child physical abuse using the CAMI criteria. Average severity of abuse across the 424 victims was $12.15(S D=1.80$; range $=6-18)$. Descriptive statistics for characteristics of physical abuse experiences are provided in the first column of Table 2 . The modal experience of physical abuse reported by victims included abuse by 2 family members (usually both parents) that involved acts such as being grabbed, shaken, slapped, pinched, or spanked so that it left a bruise or red mark that occurred 3-10 times over a period of more than 2 years that did not result in injury. However, over 100 individuals (28.1\%) reported injuries as a result of the abuse, and 3\% reported severe acts such as being choked, beaten, burned, or threatened with a weapon.

Exposure to interparental violence (IPV). Of the 1122 respondents who provided complete histories of exposure to IPV, a total of 231 (20.6\%) met the criteria for some type of exposure. Of the total sample, $192(17 \%)$ were classified as victims of exposure to physical IPV perpetrated from father-to-mother; 145 (13\%) reported mother-to-father physical violence and $106(9.4 \%)$ were exposed to IPV committed by both parents. The average severity across the 231 total victims was $11.68(S D=3.29$; range $=3-16$ ). Descriptive statistics for characteristics of exposure to IPV are provided in the first column of Table 2 . The modal experience reported was being in the room and actually witnessing moderately severe acts (i.e., slapping, biting, hitting with a minor object, throwing things, punching, or kicking) committed by both their mother and father more than 10 times over a period of more than 2 years. Over a third (36.8\%) of those reporting any IPV exposure reported altercations that led to injuries on the part of one or both parents; $18.2 \%$ reported witnessing very serious acts such as choking, being hit with a major object, burning, or threatening with or use of a weapon. 
Psychological abuse and neglect. The more varied and sometimes subtle nature of these abuse types makes firm classification of victim status more challenging. Individuals were identified as potential victims of psychological abuse or neglect if their total score on either the psychological abuse or neglect subscale was more than one standard deviation above the mean. Of the 1336 individuals who completed the CAMI psychological abuse scale, 190 (14.2\%) were classified as victims of psychological abuse (mean score on 18-point scale $=7.54$ ). The mean psychological abuse severity score was $37.85(S D=12.41)$. Of the 1339 individuals who completed the CAMI neglect scale, $203(15.2 \%)$ were classified as victims of neglect (mean score on 18 -point scale $=6.42)$. The mean neglect total score was $27.52(S D=8.13)$.

\section{Reliability of the Computer Assisted Maltreatment Inventory (CAMI)}

\section{Internal consistency}

The sexual abuse, physical abuse, and exposure to IPV subscales contain screeners followed by questions assessing specific abuse characteristics (e.g., identity and number of perpetrators; frequency, duration, and nature of acts, use of coercion), which are assigned a severity weight ranging from one to three and then summed to create an overall severity score for that abuse type. Because these discrete features do not necessarily go "hand-in-hand" (e.g., relationship to perpetrator has no bearing on type of acts), coefficient alpha is not a useful indicator of internal consistency. Consistent with this notion, corrected item-total correlations for these abuse types ranged from .18 to .48 for CSA, .16 to .37 for CPA, and .22 to .65 for exposure to IPV. In contrast, the Likert-type items of the psychological abuse and neglect scales are more amenable to traditional measures of internal consistency. In this sample, alphas for the total psychological abuse and neglect scales were .91 and .88 , respectively.

\section{Test-retest reliability}

As noted, 281 participants completed the CAMI a second time two to four weeks after the initial administration to evaluate test-retest reliability. Table 3 presents the number of researcher-defined victims of sexual abuse, physical abuse, exposure to IPV, psychological abuse, and neglect reported by all 281 retest participants across the two administrations. Participants' responses were similar across the two time points. Kappa statistics ranged from .54 to .80 with a mean of $.70(S D=.08)$, which is generally considered to reflect "good agreement" (Fleiss, 1981).

Child sexual abuse. A total of 18 individuals were classified as victims of CSA at both the test and retest. CSA severity was highly correlated across the two assessments, $r(16)=.95, p<.001$. To further examine the consistency of reports across the two administrations, each of the characteristics of CSA was examined separately (see columns 2-4 of Table 2). With the exception of the use of force, the kappa statistics for each characteristic of abuse reflected good to excellent agreement, ranging from .65 to 1.00 . The lower kappa of .38 for use of force reflected different reports from T1 to T2 on the part of 3 of the total 18 individuals.

Child physical abuse. A total of 24 individuals were classified as victims of CPA at both test and retest. CPA severity was highly correlated across the two time points, $r(22)=.82, p<.001$. To further explore the consistency of reports, each of the weighted CPA severity indicators was examined separately (see columns 2-4 of Table 2). With the exception of the duration of abuse, the kappas for these characteristics were above .60. The kappa of .45 for duration of abuse reflected changes in reporting by 2 of the 24 individuals from T1 to T2.

Exposure to interparental violence (IPV). A total of 49 individuals were classified as having been exposed to IPV at both the test and retest. Of these 49 individuals, 38 witnessed father-to-mother physical abuse and 30 witnessed mother-to-father physical abuse. Severity of exposure to IPV at test and retest was highly correlated, $r(47)=.77, p<.001$. To further examine the consistency of reports across the two administrations of the CAMI, each of the weighted severity indicators of exposure

Table 3

Agreement across test and retest administrations of the CAMI for researcher defined victims of CSA, CPA, psychological abuse, neglect, and exposure to IPV.

\begin{tabular}{|c|c|c|c|c|c|}
\hline & Time 1 Nonvictim $n$ & Time 2 Nonvictim $n$ & Time 1 Victim $n$ & Time 2 Victim $n$ & Карра \\
\hline Sexual abuse & 231 & 230 & 23 & 24 & $.74^{* *}$ \\
\hline Physical abuse & 216 & 214 & 33 & 35 & $.66^{* *}$ \\
\hline Psychological abuse & 189 & 195 & 34 & 28 & $.62^{* *}$ \\
\hline Neglect & 188 & 190 & 41 & 39 & $.61^{* *}$ \\
\hline \multicolumn{6}{|l|}{ Exposure to IPV } \\
\hline Father physical & 189 & 201 & 52 & 40 & $.79^{* *}$ \\
\hline Mother physical & 202 & 208 & 39 & 33 & $.80^{* *}$ \\
\hline Father verbal $\backslash$ emotional & 70 & 82 & 65 & 53 & $.55^{* *}$ \\
\hline Mother verbal $\backslash$ emotional & 84 & 92 & 51 & 43 & $.54^{* *}$ \\
\hline
\end{tabular}

\footnotetext{
** $p<.001$.
} 
Correlations between CAMI and CTQ total and abuse subscale scores $(n=1195)$.

\begin{tabular}{|c|c|c|c|c|c|}
\hline & \multicolumn{5}{|c|}{ CAMI subscales } \\
\hline & Total severity & Sexual abuse & Physical abuse & Psych. abuse & Neglect \\
\hline \multicolumn{6}{|l|}{ CTQ subscales } \\
\hline Total severity & $.79^{\mathrm{a}, \mathrm{a}}$ & $.37^{\mathrm{b}, \mathrm{b}}$ & $.39^{\mathrm{b}, \mathrm{b}}$ & $.78^{\mathrm{a}, \mathrm{b}}$ & $.54^{\mathrm{b}, \mathrm{a}}$ \\
\hline Sexual abuse & $.35^{\mathrm{b}, \mathrm{b}}$ & $.55^{\mathrm{a}, \mathrm{a}}$ & $.12^{\mathrm{b}, \mathrm{b}}$ & $.28^{\mathrm{b}, \mathrm{b}}$ & $.20^{\mathrm{b}, \mathrm{b}}$ \\
\hline Physical abuse & $.58^{\mathrm{b}, \mathrm{b}}$ & $.22^{\mathrm{b}, \mathrm{b}}$ & $.53^{\mathrm{a}, \mathrm{a}}$ & $.55^{\mathrm{a}, \mathrm{b}}$ & $.34^{\mathrm{b}, \mathrm{b}}$ \\
\hline Emotional abuse & $.70^{\mathrm{b}, \mathrm{b}}$ & $.27^{\mathrm{b}, \mathrm{b}}$ & $.40^{\mathrm{b}, \mathrm{b}}$ & $.74^{\mathrm{a}, \mathrm{a}}$ & $.42^{\mathrm{b}, \mathrm{b}}$ \\
\hline Emotional neglect & $.74^{\mathrm{b}, \mathrm{b}}$ & $.24^{\mathrm{b}, \mathrm{b}}$ & $.30^{\mathrm{b}, \mathrm{b}}$ & $.76^{\mathrm{a}, \mathrm{a}}$ & $.56^{\mathrm{b}, \mathrm{a}}$ \\
\hline Physical neglect & $.58^{\mathrm{b}, \mathrm{b}}$ & $.15^{\mathrm{b}, \mathrm{b}}$ & $.16^{\mathrm{b}, \mathrm{b}}$ & $.56^{\mathrm{a}, \mathrm{b}}$ & $.57^{\mathrm{a}, \mathrm{a}}$ \\
\hline
\end{tabular}

Note. All correlations significant at the $p<.01$ level. Underlined correlations represent similar subscales across the two measures. Different superscripts within a row (first superscript) or column (second superscript) indicate significantly different correlations between the underlined correlation and the others in that row or column (using Steiger's Z); identical superscripts within a row or column indicate non-significant differences.

to IPV was examined separately (see columns 2-4 of Table 2). With the exception of level of exposure and required medical attention, the kappas for these indicators were above .60 . The kappa of .42 for level of exposure reflected changes by 10 individuals from T1 to T2. For reports of injuries, the kappa of .46 represents changes by 5 individuals from T1 to T2.

Psychological abuse and physical neglect. To examine the test-retest reliability of the psychological abuse and neglect scales, correlations were computed between total psychological abuse and neglect scores for the first and second administrations of the CAMI. The correlations for psychological abuse, $r(221)=.84, p<.001$, and neglect, $r(227)=.81, p<.001$, indicated strong test-retest reliability for these two scales.

\section{Validation of the Computer Assisted Maltreatment Inventory (CAMI)}

\section{Criterion-related validity}

To examine criterion-related validity, the severity scores for the abuse subscales and total maltreatment scale of the CAMI were correlated with abuse severity scores of the CTQ. While all scores were expected to be positively associated, of particular interest was the relative strength of the correlations between similar versus different subscales on each instrument. As predicted, results in Table 4 reveal that while all abuse severity scores across the two measures were significantly and positively correlated ( $r$ s ranged from .12 to $.79, M=.46, S D=.20$ ), the highest correlations occurred between scales measuring similar abuse types ( $r$ s ranged from .53 to $.79, M=.66, S D=.12$ ). Steiger's $Z$ tests confirmed this observation by revealing significantly higher correlations between similar abuse types compared to correlations between different abuse types across both measures. Exceptions to this pattern involve the CAMI psychological abuse subscale, which had statistically equal correlations not only with the CTQ emotional abuse and emotional neglect scales (as expected), but also with the CTQ's physical neglect, physical abuse, and total scores.

\section{Social desirability}

Bivariate correlations between both abuse history measures (CAMI and CTQ) and two established measures of social desirability (MCSD, BIDR) were computed to assess possible influences of social desirability (see Table 5). The mean correlations between the abuse scales and BIDR were $r=-.08$ and $r=-.11$ for the CAMI and CTQ, respectively. Overall, the CAMI and CTQ showed consistently stronger correlations with the MCSDS than with the BIDR, with an identical mean of $r=-.16$ on both measures. However, with a range of -.07 to -.25 , the magnitude of these correlations fell mostly in the small to moderate range according to Cohen (1992). To investigate whether the associations with social desirability were significantly greater for the CAMI versus the CTQ abuse scales, the strengths of these correlations were compared using Steiger's $Z$ test for correlations within a population. Although effect sizes on both measures were small and tests of the individual subscales were non-significant, total CTQ severity was more strongly correlated with both the BIDR Self-Deceptive Enhancement subscale and BIDR total than was the total severity score of the CAMI $(Z=3.46$ and 2.96, respectively, $p<.01)$.

\section{Discussion}

A major goal of this study was to evaluate the internal and test-retest reliability of the CAMI. Coefficients alpha for the CAMI's Likert-type psychological abuse and neglect scales were high, likely reflecting the underlying nature of these abuse types, which tend to represent enduring conditions within the family system rather than sporadic acts of aggression that typify child sexual and physical abuse (O'Hagan, 1993). Regarding temporal stability, the present study may be the first to examine the consistency of self-reported maltreatment across multiple abuse types, not only at the basic level of victim status (abused vs. not), but also at the more detailed level of abuse characteristics. Results reflected generally good agreement at both levels. Regarding abuse classification, the vast majority of participants who reported being victimized (or not) at Time 1 
Table 5

Correlations between social desirability measures and child maltreatment subscales.

\begin{tabular}{|c|c|c|c|c|}
\hline & \multicolumn{4}{|c|}{ Social desirability measures } \\
\hline & BIDR Imp Mgmt & BIDR Self-Dec & BIDR Total & MCSDS Total \\
\hline \multicolumn{5}{|l|}{ CAMI subscales } \\
\hline Sexual abuse & .01 & $-.08^{* *}$ & -.04 & $-.07^{*}$ \\
\hline Physical abuse & -.01 & $-.09^{* *}$ & $-.06^{*}$ & $-.13^{* *}$ \\
\hline Exposure to IPV & $-.13^{* *}$ & -.01 & $-.09^{* *}$ & $-.14^{* *}$ \\
\hline Psychological abuse & $-.09^{* *}$ & $-.16^{* *}$ & $-.15^{* *}$ & $-.23^{* *}$ \\
\hline Neglect & -.03 & $-.10^{* *}$ & $-.08^{* *}$ & $-.14^{* *}$ \\
\hline Total maltreatment & -.06 & $-.11^{* *}$ & $-.10^{* *}$ & $-.23^{* *}$ \\
\hline Mean & -.06 & -.09 & -.09 & -.16 \\
\hline \multicolumn{5}{|l|}{ CTQ subscales } \\
\hline Sexual abuse & .02 & $-.08^{* *}$ & -.04 & $-.08^{* *}$ \\
\hline Physical abuse & -.05 & $-.13^{* *}$ & $-.11^{* *}$ & $-.12^{* *}$ \\
\hline Emotional abuse & $-.11^{* *}$ & $-.19^{* *}$ & $-.18^{* *}$ & $-.25^{* *}$ \\
\hline Emotional neglect & $-.09^{* *}$ & $-.16^{* *}$ & $-.15^{* *}$ & $-.21^{* *}$ \\
\hline Physical neglect & -.04 & $-.10^{* *}$ & $-.08^{* *}$ & $-.10^{* *}$ \\
\hline Total CTQ & $-.08^{* *}$ & $-.18^{* *}$ & $-.16^{* *}$ & $-.22^{* *}$ \\
\hline Mean & -.08 & -.14 & -.12 & -.16 \\
\hline
\end{tabular}

reported the same at Time 2, across all types assessed. The largest fluctuations were found in reports of exposure to parental verbal/emotional abuse. Unlike other abuse types, however, this classification is based on responses to a single item, which may have led to less reporting consistency. Among those classified as victims of sexual abuse, physical abuse, and exposure to violence, reports about the characteristics of these experiences, including the number and identity of perpetrators and the nature, frequency, and duration of acts, were largely consistent over time. Where kappas fell below desirable levels, this tended to reflect small shifts in certain categories (e.g., degree of force or exposure to IPV) among a few individuals. Future research might explore whether these abuse characteristics are especially susceptible to reporting fluctuations. The total psychological abuse and neglect scores showed sufficient test-retest reliability ( $r s=.84$ and .81 , respectively). Finally, across all five maltreatment types, there was strong temporal stability in the composite severity scores ( $r$ s ranging from .77 to .95). Although these figures provide initial data supporting the CAMI's stability in assessing abuse status and characteristics, future studies should use larger samples of victims and longer test-retest periods.

An additional goal of this study was to examine the validity of the CAMI abuse severity scores through comparisons to corresponding scales on the CTQ. As expected, all maltreatment types were modestly intercorrelated across the two measures, which is consistent with prior findings documenting the co-occurrence of various forms of maltreatment (Dong et al., 2004). The strongest associations tended to be between similar scales across the two measures, lending support to the ability of the CAMI to discriminate between specific forms of maltreatment. These results are especially notable given the fundamentally different approaches of each measure. One curious finding was that the CAMI's psychological abuse subscale showed statistically similar correlations not only with the CTQ emotional abuse and neglect scales (as predicted), but also with the physical neglect, physical abuse, and CTQ total scores. Although counter to expectations, this result may reflect the role of psychological maltreatment as a "common thread" that often occurs in conjunction with other forms of maltreatment, including sexual and physical abuse (Dong et al., 2004; Hart et al., 2002). Conceptually, it is easy to envision how psychological abuse as assessed by the CAMI (e.g., denial of emotional responsiveness, terrorizing) might coincide with other abuse types.

We also examined socially desirable response bias, with the hypothesis that the CAMI's more graphic content would show greater associations with measures of social desirability than would the CTQ. Unexpectedly, the CAMI severity scales were no more, and, in the case of the MCSDS, less related to measures of social desirability than were the CTQ scores. However, both abuse measures showed stronger relations with the MCSDS than with either the impression management or self-deceptive enhancement components of the BIDR, indicating that self-reported abuse history may be more vulnerable to the approval seeking aspect of social desirability that is tapped by the MCSDS. Despite these patterns, the correlations here were generally low in magnitude and no greater than those found between social desirability and common personality and clinical symptom measures (e.g., Beck et al., 2004).

Limitations of the present study highlight directions for future efforts in the development of the CAMI. First, our sample was relatively uniform with respect to age, fairly high in socioeconomic status, and contained proportionately fewer males than females. Because these factors may limit the generalizability of findings, future work should include the broader population of both women and men who have experienced various types of maltreatment. The lack of definitive cut scores on the psychological abuse and neglect scales also should be noted. In contrast to sexual and physical abuse, which can be defined through a finite set of behaviors, the more varied and subtle nature of these abuse types makes it difficult to discern inappropriate but sub-threshold parenting from clearly abusive practices. Here, one standard deviation above the mean was used to distinguish non-victims from those whose experiences were classified as abusive-a strategy that yielded preva- 
lence rates consistent with other studies. Nevertheless, because this technique produces sample-specific cut scores, future investigations might use ROC or similar analyses to establish more universal cut offs. Finally, although a well-established measure was used to examine criterion-related validity, the CTQ is also a retrospective self-report instrument. Thus, there is a need to further validate the CAMI using independent accounts of maltreatment obtained at the time of the abuse (e.g., from CPS records).

Findings from this study build on others in suggesting that the CAMI is a promising tool for the retrospective assessment of childhood maltreatment. Unlike scaled instruments, the CAMI's behaviorally descriptive format yields rich data about what actually transpired in abusive encounters with each perpetrator. The CAMI's computerized format provides a relatively efficient means by which to acquire these data. Finally, information obtained with the CAMI can be used to operationalize abuse according to a researcher's needs as well as to produce dimensional severity scores that are supported by the present findings showing short-term temporal stability and expected patterns of convergent and discriminant correlations with a criterion measure.

\section{References}

Anda, R. F., Felitti, V. J., Bremner, J. D., Walker, J. D., Whitfield, C., Perry, B. D., Dube, S. R., \& Giles, W. H. (2006). The enduring effects of abuse and related adverse experiences in childhood: A convergence of evidence from neurobiology and epidemiology. European Archives of Psychiatry and Clinical Neuroscience, 256, 174-186.

Appel, A. E., \& Holden, G. W. (1998). The co-occurrence of spouse and physical child abuse: A review and appraisal. Journal of Family Psychology, $12,578-599$. Barger, S. D. (2002). The Marlowe-Crowne affair: Short forms, psychometric structure and social desirability. Journal of Personality Assessment, $79,286-305$. Beck, J. G., Coffey, S. F., Palyo, S. A., Gudmundsdottir, B., Miller, L. M., \& Colder, C. R. (2004). Psychometric properties of the Posttraumatic Cognitions Inventory (PTCI): A replication with motor vehicle accident survivors. Psychological Assessment, 16, 289-298.

Beretvas, S. N., Meyers, J. L., \& Leite, W. L. (2002). A reliability generalization study of the Marlowe-Crowne Social Desirability Scale. Educational and Psychological Measurement, 62, 570-589.

Bernstein, D. P., \& Fink, L. (1998). Childhood Trauma Questionnaire. San Antonio, TX: Psychological Corporation.

Bernstein, D. P., Fink, L., Handelsman, L., Foote, J., Lovejoy, M., Wenzel, K., Sapareto, E., \& Ruggiero, J. (1994). Initial reliability and validity of a new retrospective measure of child abuse and neglect. American Journal of Psychiatry, 151, 1132-1136.

Bernstein, D. P., Stein, J. A., Newcomb, M. D., Walker, E., Pogge, D., Ahluvalia, T., Stokes, J., Handelsman, L., Medrano, M., Desmond, D., \& Zule, W. (2003). Development and validation of a brief screening version of the Childhood Trauma Questionnaire. Child Abuse E' Neglect, 27, $169-190$.

Bifulco, A., Moran, P. M., Baines, R., Bunn, A., \& Stanford, K. (2002). Exploring psychological abuse in childhood. II. Association with other abuse and adult clinical depression. Bulletin of the Menninger Clinic, 66, 241-266.

Clemmons, J. C., DiLillo, D., Martinez, I. G., DeGue, S., \& Jeffcott, M. (2003). Co-occurring forms of child maltreatment and adult adjustment reported by Latina college students. Child Abuse E' Neglect, 27, 751-767.

Cohen, J. (1992). A power primer. Psychological Bulletin, 112, 155-159.

Crowne, D. P., \& Marlowe, D. (1960). A new scale of social desirability independent of psychopathology. Journal of Consulting Psychology, 24, 349-354.

D'Cruz, H. (2004). The social construction of child maltreatment: The role of medical practitioners. Journal of Social Work, 4, $99-123$.

DiLillo, D., DeGue, S., Kras, A., Di Loreto-Colgan, A., \& Nash, C. L. (2006). Participant responses to retrospective surveys of child maltreatment: Does mode of assessment matter? Violence and Victims, 21, 242-409.

DiLillo, D., Fortier, M. A., Hayes, S. A., Trask, E., Perry, A. R., Messman-Moore, T. L., Messman-Moore, T., Fauchier, A., \& Nash, C. (2006). Retrospective assessment of childhood sexual and physical abuse: A comparison of scaled and behaviorally specific approaches. Assessment, 13, 297-312.

Dong, M., Anda, R. F., Felitti, V. J., Dube, S. R., Williamson, D. F., Thompson, T. J., Loo, C. M., \& Giles, W. H. (2004). The interrelatedness of multiple forms of childhood abuse, neglect, and household dysfunction. Child Abuse E Neglect, 28, 771-784.

Dutton, D. G., \& Hemphill, K. J. (1992). Patterns of socially desirable responding among perpetrators and victims of wife assault. Violence and Victims, 7, 29-39.

English, D. J., Upadhyaya, M. P., Litrownik, A. J., Marshall, J. M., Runyan, D. K., Graham, J. C., \& Dubowitz, H. (2005). Maltreatment's wake: The relationship of maltreatment dimensions to child outcomes. Child Abuse E Neglect, 29, 597-619.

Fleiss, J. (1981). Statistical methods for rates and proportions (2nd ed.). New York: John Wiley \& Sons.

Fricker, A. E., Smith, D. W., Davis, J. L., \& Hanson, R. F. (2003). Effects of context and question type on endorsement of childhood sexual abuse. Journal of Traumatic Stress, 16, 265-268.

Friedrich, W. N., Talley, N. J., Panser, L., Fett, S., \& Zinsmeister, A. R. (1997). Concordance of reports of childhood abuse by adults. Child Maltreatment, 2, $164-171$.

Hart, S. N., Brassard, M. R., Binggeli, N. J., \& Davidson, H. A. (2002). Psychological maltreatment. In J. E. B. Myers, L. Berliner, J. Briere, C. T. Hendrix, C. Jenny, \& T. A. Reid (Eds.), The APSAC handbook on child maltreatment (2nd ed., pp. 79-103). Thousand Oaks, CA: Sage.

Higgins, D. J., \& McCabe, M. P. (2001). Multiple forms of child abuse and neglect: Adult retrospective reports. Aggression and Violent Behavior, 6, 547-578.

Hulme, P. A. (2004). Retrospective measurement of childhood sexual abuse: A review of instruments. Child Maltreatment, 9, $201-217$.

Kitzmann, K. M., Gaylord, N. K., Holt, A. R., \& Kenny, E. D. (2003). Child witness to domestic violence: A meta-analytic review. Journal of Consulting and Clinical Psychology, 71, 339-352.

Lowe, W., Jr., Pavkov, T. W., Casanova, G. M., \& Wetchler, J. L. (2005). Do American ethnic cultures differ in their definitions of child sexual abuse? American Journal of Family Therapy, 33, 147-166.

Meston, C. M., Heiman, J. R., Trapnell, P. D., \& Paulhus, D. L. (1998). Socially desirable responding and sexuality self-reports. Journal of Sex Research, 35, $148-157$.

Mohr, W. K., Noone Lutz, M. J., Fantuzzo, J. W., \& Perry, M. A. (2000). Children exposed to family violence: A review of empirical research from a developmental-ecological perspective. Trauma, Violence E Abuse, 1, 264-283.

Molnar, B. E., Buka, S. L., \& Kessler, R. C. (2001). Child sexual abuse and subsequent psychopathology: Results from the national comorbidity survey. American Journal of Public Health, 91, 753-760.

Nash, C. L. (2006). Reliability, validity, and factor structure of the Psychological Abuse and Neglect Scales of the Computer Assisted Maltreatment Inventory (CAMI). (Doctoral dissertation, University of Nebraska-Lincoln, 2006). Dissertation Abstracts International, 66, 4494.

Nelson, E. C., Heath, A. C., Madden, P. A. F., Cooper, M. L., Dinwiddie, S. H., Bucholz, K. K., Glowinski, A. L., \& McLaughlin, T. (2002). Association between self-reported childhood sexual abuse and adverse psychosocial outcome: Results from a twin study. Archives of General Psychiatry, $59,139-145$.

O'Hagan, K. (1993). Emotional and psychological abuse of children. Toronto, Canada: University of Toronto Press.

Paulhus, D. L. (1984). Two-component models of socially desirable responding. Journal of Personality and Social Psychology, $46,598-609$.

Paulhus, D. L. (1991). Measurement and control of response bias. In J. P. Robinson, P. R. Shaver, \& L. S. Wrightsman (Eds.), Measures of personality and social psychological attitudes: Volume 1: Measures of social psychological attitudes (pp. 17-59). San Diego, CA: Academic Press.

Paulhus, D. L. (1994). Balanced Inventory of Desirable Responding: Reference manual for BIDR Version 6. Unpublished manuscript. University of British Columbia. 
Rind, B., Tromovitch, P., \& Bauserman, R. (1998). A meta-analytic examination of assumed properties of child sexual abuse using college samples. Psychological Bulletin, 124, 22-53.

Roy, C. A., \& Perry, J. C. (2004). Instruments for the assessment of childhood trauma in adults. Journal of Nervous and Mental Disease, 192, $343-351$.

Sedlak, A., \& Broadhurst, D. D. (1996). Third national incidence study of child abuse and neglect: Final report. Washington DC: U.S. Department of Health and Human Services.

Silvern, L., Waelde, L. C., Baughan, B. M., Karyl, J., \& Kaersvang, L. L. (2000). Two formats for eliciting retrospective reports of child sexual and physical abuse: Effects on apparent prevalence and relationships to adjustment. Child Maltreatment, 5, 236-250.

Smith, N., Lam, D., Bifulco, A., \& Checkley, S. (2002). Childhood Experience of Care and Abuse Questionnaire (CECA.Q): Validation of a screening instrument for childhood adversity in clinical populations. Social Psychiatry and Psychiatric Epidemiology, 37, 572-579.

Straus, M. A., Hamby, S. L., Boney-McCoy, S., \& Sugarman, D. B. (1996). The Revised Conflict Tactics Scales (CTS2), development and preliminary psychometric data. Journal of Family Issues, 17, 283-316.

Whipple, E. E., \& Richey, C. A. (1997). Crossing the line from physical discipline to child abuse: How much is too much? Child Abuse E Neglect, 21, 431-444. 